\title{
Fungal infection, decline, and persistence in the only obligate troglodytic Neotropical salamander
}

\author{
Mizraim Olivares-Miranda ${ }^{1}$, Vance T Vredenburg ${ }^{2}$, Julio C García-Sánchez ${ }^{1}$, Allison Q Byrne ${ }^{3}$, Erica B Rosenblum \\ 3 , Sean M Rovito ${ }^{\text {Corresp. } 1}$ \\ 1 Unidad de Genómica Avanzada (Langebio), Centro de Investigación y de Estudios Avanzados del Instituto Politécnico Nacional, Irapuato, Guanajuato, \\ México \\ 2 Department of Biology, San Francisco State University, San Francisco, California, United States \\ 3 Department of Environmental Science, Policy, and Management, University of California, Berkeley, Berkeley, California, United States \\ Corresponding Author: Sean M Rovito \\ Email address: sean.rovito@cinvestav.mx
}

The fungal pathogen Batrachochytrium dendrobatidis $(B d)$ is implicated in global mass dieoffs and declines in amphibians. In Mesoamerica, the $B d$ epidemic wave hypothesis is supported by detection of $B d$ in historic museum specimens collected over the last century, yet the timing and impact of the early stages of the wave remain poorly understood. Chiropterotriton magnipes, the only obligate troglodytic Neotropical salamander, was abundant in its small range in the decade following its description in 1965, but subsequently disappeared from known localities and was not seen for 34 years. Its decline is roughly coincident with that of other populations of Neotropical salamanders associated with the invasion and spread of $B d$. To determine the presence and infection intensity of $B d$ on $C$. magnipes and sympatric amphibian species (which are also $B d$ hosts), we used a noninvasive sampling technique and qPCR assay to detect $B d$ on museum specimens of $C$. magnipes collected from 1952 to 2012, and from extant populations of $C$. magnipes and sympatric species of amphibians. We also tested for the presence of the recently discovered Batrachochytrium salamandivorans (Bsal), another fungal chytridiomycete pathogen of salamanders, using a similar technique specific for Bsal. We did not detect $B d$ in populations of $C$. magnipes before 1969 , while $B d$ was detected at low to moderate prevalence just prior to and during declines. This pattern is consistent with $B d$-caused epizootics followed by host declines and extirpations described in other hosts. We did not detect Bsal in any extant population of $C$. magnipes. We obtained one of the earliest positive records of the fungus to date in Latin America, providing additional historical evidence consistent with the $B d$ epidemic wave hypothesis. Genotyping results show that at least one population is currently infected with the Global Panzootic Lineage of $B d$, but our genotyping of the historical positive samples was unsuccessful. The lack of large samples from some years and the difficulty in genotyping historical Bd samples 
illustrate some of the difficulties inherent in assigning causality to historical amphibian declines. These data also provide an important historical baseline for actions to preserve the few known remaining populations of Chiropterotriton magnipes. 
1 Fungal infection, decline, and persistence in the only obligate troglodytic Neotropical

2 salamander

5 Mizraim Olivares-Miranda ${ }^{1}$, Vance T. Vredenburg², Julio César García-Sánchez ${ }^{1}$, Allison Q.

6 Byrne $^{3}$, Erica Bree Rosenblum ${ }^{3}$, and Sean Michael Rovito ${ }^{1}$

7

$8{ }^{1}$ Unidad de Genómica Avanzada (Langebio), Centro de Investigación y de Estudios Avanzados

9 del Instituto Poltécnico Nacional, Irapuato, Guanajuato, México

102 Department of Biology, San Francisco State University, San Francisco, California, USA

$11{ }^{3}$ Department of Environmental Science Policy and Management, University of California,

12 Berkeley, California, USA

14 Corresponding Author:

15 Sean Rovito

16 Km 9.6 Libramiento Norte Carretera Irapuato-León, Irapuato, Guanajuato CP36824, México

17 Email address: sean.rovito@cinvestav.mx

19 Abstract

20 The fungal pathogen Batrachochytrium dendrobatidis $(B d)$ is implicated in global mass die-offs

21 and declines in amphibians. In Mesoamerica, the $B d$ epidemic wave hypothesis is supported by

22 detection of $B d$ in historic museum specimens collected over the last century, yet the timing and

23 impact of the early stages of the wave remain poorly understood. Chiropterotriton magnipes, the 
24 only obligate troglodytic Neotropical salamander, was abundant in its small range in the decade 25 following its description in 1965, but subsequently disappeared from known localities and was

not seen for 34 years. Its decline is roughly coincident with that of other populations of Neotropical salamanders associated with the invasion and spread of $B d$. To determine the presence and infection intensity of $B d$ on $C$. magnipes and sympatric amphibian species (which are also $B d$ hosts), we used a noninvasive sampling technique and qPCR assay to detect $B d$ on museum specimens of C. magnipes collected from 1952 to 2012, and from extant populations of C. magnipes and sympatric species of amphibians. We also tested for the presence of the recently discovered Batrachochytrium salamandivorans (Bsal), another fungal chytridiomycete pathogen of salamanders, using a similar technique specific for $B$ sal. We did not detect $B d$ in populations of $C$. magnipes before 1969 , while $B d$ was detected at low to moderate prevalence just prior to and during declines. This pattern is consistent with $B d$-caused epizootics followed by host declines and extirpations described in other hosts. We did not detect Bsal in any extant population of $C$. magnipes. We obtained one of the earliest positive records of the fungus to date in Latin America, providing additional historical evidence consistent with the $B d$ epidemic wave hypothesis. Genotyping results show that at least one population is currently infected with the Global Panzootic Lineage of $B d$, but our genotyping of the historical positive samples was unsuccessful. The lack of large samples from some years and the difficulty in genotyping historical Bd samples illustrate some of the difficulties inherent in assigning causality to historical amphibian declines. These data also provide an important historical baseline for actions to preserve the few known remaining populations of Chiropterotriton magnipes. 
48

49

50

51

52

53

54

55

56

57

58

59

60

61

62

63

64 65 66

67 68

\section{Introduction}

Chytridiomycosis, a fungal disease caused by Batrachochytrium dendrobatidis $(B d)$ and Batrachochytrium salamandrivorans (Bsal), is recognized as a driver of amphibian population declines and extirpations on a global scale, which many believe is indicative of a sixth mass extinction on earth (Wake and Vredenburg 2008; Scheele et al. 2019). One particular lineage of $B d$, the Global Panzootic Lineage (Bd-GPL), is particularly virulent and associated with most documented declines (Farrer et al. 2011). In many of the most affected areas, such as Central America, South America, and Australia, Bd-GPL appears to have been historically absent (prior to the 1970s) and amphibian declines followed after $B d$ invaded and rapidly increased in prevalence and in geographical distribution (Cheng et al. 2011; Lips 2016). Despite the apparent recent and rapid spread of Bd-GPL to many parts of the world, recent genomic studies indicate that some areas (including South America) may have long harbored other endemic lineages of $B d$ (O'Hanlon et al. 2018; Byrne et al. 2019), complicating interpretation of declines when direct evidence of chytridiomycosis-associated mortality is lacking.

2 Latin America, home of tremendous amphibian diversity, has some of the most $B d$-impacted populations in the world, with major declines in both frogs and salamanders at multiple sites from the 1970s onward (Young et al. 2001; La Marca et al. 2005; Rovito et al. 2009; Catenazzi et al. 2011). The earliest published records of $B d$ in Mesoamerica are from Costa Rica in the 1960s, predating $B d$ epizootics in that country, and from Mexico in the early 1970 s where its arrival was temporally coincident with major declines in salamanders (Rovito et al. 2009; Cheng et al. 2011). About two decades later, $B d$-epizootics were directly documented in southeastern 
69 Costa Rica and Panama (Berger et al. 1998; Lips 1998; Lips et al. 2006) and provided some of

70 the foundational data used to describe $B d$ in 1999 (Longcore et al. 1999).

71 The epidemic wave hypothesis (Lips et al. 2006; Lips et al. 2008) states that Bd-GPL moved

72 through naïve amphibian host species, causing massive population declines and extirpations.

73 Currently available data on declines from Latin American in the late $20^{\text {th }}$ century, bolstered by

74 retrospective museum surveys, generally support this hypothesis, but many key elements of this

75 paradigm remain incompletely understood. According to one hypothesized sequence of events,

$76 B d$ invaded Mexico and Guatemala first and spread southeast, yet despite many species that have

77 declined in Mexico and Guatemala, relatively few historical amphibian declines have been

78 linked to $B d$ (Cheng et al. 2011; Mendelson et al. 2014). Furthermore, recent work on $B d$

79 genomics (O'Hanlon et al. 2018; Byrne et al. 2019) reveals that multiple $B d$ lineages can coexist

80 in some regions, and may have differential impact on host health. A $B d$-positive frog specimen

81 from the Bolivian Andes collected in 1863, long before declines of cloud forest amphibians in

82 that country in the early 1990s, shows that $B d$ has been present in South America long before

83 reported epizootics. This early positive record was detected by qPCR, and histological

84 examination was suggestive but inconclusive (Burrowes and De la Riva 2017). In cases of very

85 early detection of $B d$ in countries where declines occurred much later, it is possible that early

86 detections correspond to endemic strains while declines were caused only by the arrival of the

87 more virulent Bd-GPL, but genetic data to support this hypothesis are currently lacking

88 (Burrowes and De la Riva 2017; Burrowes et al. 2020). Retrospective surveys of key species in

89 museum collections, together with the use of genomic methods to identify $B d$ lineage, offer a

90 promising avenue to fill gaps in our knowledge related to the arrival and impact of $B d$ in the

91 Neotropics. 
92 Compared to other Neotropical countries, Mexico is particularly rich in salamander species, 93 with the second highest number of species of any country (157 described species; AmphibiaWeb 94 2020). The large majority of these species belong to a single family, the Plethodontidae, which 95 has experienced an evolutionary radiation in the mountains of Mexico. Among its many endemic 96 plethodontids, Mexico has the only troglodytic (cave-dwelling) salamander species in the

97 Neotropics. The single obligate troglodytic species, Chiropterotriton magnipes, was described in 981965 (Rabb 1965) and was known from a small number of caves in the states of Querétaro and 99 San Luis Potosí. Its unique morphology (massive fully webbed feet, protruding eyes, mostly 100 unpigmented skin) make it unique among Neotropical salamanders, and thus of high evolutionary significance. It was initially abundant at several localities and is well represented in museum collections from the 1960s and 1970s, but later became scarce and was not seen from 1982 until 2005 (Parra-Olea et al. 2008). In recent years, it has been found at a small number of

104 localities in low abundance compared to the decade following its description (S. Rovito, pers. obs.). Because most cave habitat at known sites apparently remains largely intact (although not without human impact), the causes of decline are not apparent, and thus infectious disease could be involved. Understanding the cause of past declines is thus critical to designing effective conservation strategies to ensure its persistence.

While the approximate timing of declines coincides with those seen at other localities in central Mexico (Cheng et al. 2011), the range of $C$. magnipes is farther north than any of these

111 localities. The large number of specimens from the pre-decline period present in museums, together with a small number of specimens from the period of decline, allowed us to test whether

113 the timing of arrival of $B d$ (if present) in these populations coincides with their declines. Thus,

114 we combine retrospective surveys of nearly all specimens of this species in museum collections 
115 to test this hypothesis. We also use recently developed genotypic methods that employ small

116 amounts of DNA to genotype present day $B d$-positive samples from remaining populations of $C$.

117 magnipes and we attempt to genotype historical $B d$-positive specimens to identify which $B d$

118 lineage might have been involved in declines. By understanding the role of $B d$ in historical

119 declines and its current impact on remnant populations, we suggest a conservation strategy for

120 this threatened and emblematic Mexican salamander.

121

122 Materials \& Methods

123 Historical prevalence of $B d$ in museum specimens of C. magnipes

124 We obtained skin swab samples from 279 formalin-preserved museum specimens of $C$.

125 magnipes collected in Mexico from 1952 to 2012. Our sample included six specimens identified

126 only as Chiropterotriton sp. from a historical locality of C. magnipes collected in 1981 and 1982.

127 The specimens are housed at the University of Michigan Museum of Zoology (UMMZ),

128 Museum of Vertebrate Zoology, University of California, Berkeley (MVZ), Biodiversity

129 Research and Teaching Collections, Texas A\&M University (TCWC), Field Museum of Natural

130 History (FMNH), Museum of Comparative Zoology, Harvard University (MCZ) and the

131 Louisiana State University Museum of Zoology (LSUMZ). Before sampling, each specimen was

132 rinsed with $70 \% \mathrm{EtOH}$ to avoid contamination by errant skin pieces or floating $\mathrm{Bd}$ zoospores

133 possibly contained in the preservation jars. Multiple specimens (sometimes over 100) of $C$.

134 magnipes were stored in a single jar, particularly in the MVZ where the bulk of our sample is

135 from. While rinsing specimens should reduce the probability of cross contamination, transfer of

$136 B d$ DNA or zoospores between samples within a jar cannot be excluded using our methodology.

137 Using nitrile gloves and sterile Medical Wire Dryswabs (MW113; Medical Wire \& Equipment

Peer] reviewing PDF | (2020:05:48948:1:1:NEW 21 Jul 2020) 
138 Co, Corsham, UK), we swabbed each specimen 30 times (ten strokes for the ventral surface and

139 five strokes per ventral part of the feet). Nitrile gloves were changed between specimens and the 140 swabs were air dried and stored at $-20^{\circ} \mathrm{C}$ until processing.

141 We extracted DNA following the standard extraction protocol for PrepMan Ultra (Applied

142 Biosystems, Foster City, CA). All the extractions were diluted in 0.25X TE buffer and used as

143 template for the quantitative Polymerase Chain Reaction (qPCR) assay with modifications for

144 detection of zoospore genomic equivalents (GE) of $B d$ in historical samples (Cheng et al. 2011).

145 We used the primers and probe developed by Boyle et al. (2004) and the ABI 7300 real-time

146 PCR system at San Francisco State University to amplify the genomic region ITS3-5.8S of $B d$.

147 We ran the samples along with $B d$-positive controls at the dilution levels of $0.1,1.0,10$ and 100

$148 \mathrm{GE}$ (three positive controls per dilution level per plate) and negative controls (water and TE

149 buffer, four total per plate) to detect false positives. All samples were run in triplicate and were

150 considered as $B d$-positive when one of the three reactions returned a positive quantification $(>0$

$151 \mathrm{GE}$ ) and when the reaction curve of the positive samples showed an exponential tendency

152 according to the $B d$ positive controls, with the standard reaction curves generated having a $\mathrm{R}^{2}$

153 value $>0.99$. Because this qPCR assay may not return accurate values of $B d$-infection intensity

154 for historical formalin-preserved $B d$-positive samples (Cheng et al. 2011), the results of the

155 qPCR assay were treated only as $B d$-positive or negative.

156

157 Current prevalence of Bd/Bsal

158 We conducted searches for C. magnipes at four historical sites, two recently discovered

159 populations, and eight caves where salamanders had not previously been reported (Table 1, Fig.

160 1). Searches consisted of scanning cave walls, ceiling, and floor with headlamps until the entire 
161 accessible area had been surveyed. Each cave was searched between one and six times,

162 depending on its assessed potential for salamander presence (Table 1). Surveys and manipulation

163 of amphibians were conducted in accordance with the guideline of the Institutional Care and Use

164 of Laboratory Animals Committee of the SIACUAL System of Cinvestav, Mexico (Protocol

165 0291-19 to Sean Rovito). Permits for field research were provided by the Secretaría del Medio

166 Ambiente y Recursos Naturales (SEMARNAT permit SGPA/DGVS/002764/18 to Sean Rovito).

167 In order to estimate the prevalence of $B d$ in the few caves where we found extant

168 populations of C. magnipes, we obtained skin swabs from live C. magnipes from two localities

169 of Mexico (La Trinidad, San Luis Potosí and El Coni, Durango, Hidalgo; Table 1, Figure 1) in

1702017 and 2018. We did not mark animals to avoid compromising their health in any way but did

171 note age class (adult/juvenile) and sex to determine the minimum number of individuals

172 sampled. We also took skin swabs from two salamander and two frog species found in sympatry

173 in caves with C. magnipes: Chiropterotriton mosaueri, Aquiloeurycea sp., Craugastor decoratus

174 and Eleutherodactylus cystignathoides. With the exception two juvenile C. magnipes sampled at

175 La Trinidad, all salamanders and frogs tested for $B d$ were adults or subadults. We captured each

176 individual in a clean plastic bag inside the cave. Each individual amphibian was rinsed with 100

$177 \mathrm{~mL}$ of sterile water and nitrile gloves were changed between specimens to avoid cross

178 contamination. We use sterile a Medical Wire Dryswab (MW113) to swab each individual 30

179 times using a standard sampling protocol (Hyatt et al. 2007). Individuals were released

180 immediately after being swabbed. We obtained 29 skin swab samples, which were stored in 1.5

$181 \mathrm{~mL}$ cryogenic tubes in liquid nitrogen for transport to the lab, and subsequently at $-80^{\circ} \mathrm{C}$ until

182 processing. 
184 for $B d$ as described in the previous section. A second qPCR assay for Bsal was performed in the 185 Catenazzi Lab at the Florida International University using the primers and probe developed by 186 Blooi et al. (2013), adding to the reaction plate Bsal positive controls and negative controls to 187 detect false positives. All samples were run in duplicate and were regarded as $B d$ or $B s a l$ positive 188 when the two duplicates returned a positive quantification $(>0 \mathrm{GE})$ and when the reaction curve 189 of the positive samples shows an exponential tendency according to the $B d / B$ sal positive 190 controls, with the standard reaction curves generated having a $\mathrm{R}^{2}$ value $>0.99$. The mean 191 quantity output data of the positive qPCR results were multiplied by 80 (to account the dilution 192 factor) to obtain the mean infection intensity of the swab collected for each animal.

194 Genotype of positive samples for Bd

195 We used a multiplexed microfluidic PCR approach (Byrne et al. 2017) to attempt to genotype Bd from six 196 historical museum swabs and two field-collected swabs (from El Coni, Hidalgo) of C. magnipes that 197 tested positive for $B d$ using the qPCR assay. Briefly, this approach uses an isopropanol precipitation 198 followed by a pre-amplification enrichment step. Samples are then amplified at 192 loci selected to 199 discriminate between Bd lineages. Loci were amplified in a Fluidigm Access Array (Fluidigm, South San 200 Francisco, CA) and sequenced on an Illumina MiSeq v3 sequencer at The University of Idaho IBEST 201 Genomics Resources Core. This method has been shown to work well when DNA extracts from swab 202 samples and accurately discriminates between known $B d$ lineages (Byrne et al. 2019). The 203 multilocus sequence data used for Bd genotyping are accessible via the NCBI Short Read 204 Archive (BioProject ID PRJNA608001).

205 Raw sequence reads were processed as described in Byrne et al. (2017). Briefly, reads 206 were joined using FLASH (v.1.2.11) (Magoc and Salzberg 2011) and consensus sequences were 
207 produced from sequence variants represented by at least 5 reads and $5 \%$ of total reads for that 208 sample/amplicon combination. Multiple alleles at an individual locus were represented using 209 IUPAC ambiguity codes. To determine what $B d$ lineage was represented in the available 210 samples, we used a gene tree to species tree approach. First, we selected newly genotyped 211 samples with at least 20 amplicon sequences $(\mathrm{N}=1)$. Next, we combined our newly genotyped 212 sample with 105 previously published globally distributed samples (Byrne et al. 2017; O'Hanlon 213 et al. 2018). We selected amplicons with no more than 50\% missing data ( $\mathrm{N}=185)$, individually 214 aligned all amplicon sequences using MUSCLE package (v.3.18.0) (Edgar 2004) in R (v.3.4.3) 215 (R Development Core Team 2015) and produced gene trees using RAxML (v.8.2.11) 216 (Stamatakis 2014) to search for the best-scoring ML tree from 100 bootstrap replicates. We 217 collapsed all nodes with less than 10 bootstrap support and used these collapsed gene trees as 218 input to Astral-III (v.5.5.9) (Zhang et al. 2018). Astral estimates an unrooted species tree given 219 unrooted gene trees and allows for missing data across gene trees. Finally, we collapsed all nodes 220 in the Astral species tree with a posterior less than 0.7.

221

222 Statistical analysis

223 For the historical specimens, $B d$ prevalence for each year was calculated dividing the total of $B d$ 224 positive $C$. magnipes specimens by the total of specimens sampled. For years with zero $B d$ 225 prevalence, we calculate the probability of a false negative using the formula $(1-0.05)^{S}$, where $226 S$ represents the sample size of the year and taking in count a true $B d$ prevalence of 0.05 in the 227 population (Cheng et al. 2011). Current $B d$ and Bsal prevalence for each species and locality was 228 calculated dividing the total of $B d / B$ sal positive individuals by the total of individuals sampled. 229 We then calculated 95\% confidence intervals using the Clopper-Pearson test (also known as an 
230 exact binomial distribution confidence interval test) using the package 'PropsC'. All statistical 231 analyses were performed in $\mathrm{R}$ version 3.4.1.

232

\section{Results}

234

Historical Bd prevalence in populations of C. magnipes

235 We found a pattern of emergence of $B d$ in the study consistent with the arrival of $B d$ to naïve 236 amphibian populations. From 1952 to 1968, all samples were negative for $B d(\mathrm{~N}=91)$, and all 237 positive samples were found in the period 1969-1982. Considering all the historical preserved 238 specimens of $C$. magnipes sampled, we found a $B d$ prevalence of $2.5 \%$ (7/279) (Table 2). The earliest record of a $B d$-positive animal came from a single specimen collected in 1969, representing $1.2 \%(1 / 81)$ of the total sampled specimens from that year. We obtained $B d-$ positive specimens in subsequent years $(1970,1975,1981$ and 1982). For the period prior to the

242 first detection of $B d(1952-1968)$ and for the years with relatively large sample sizes (1964 and 243 1968), we calculated the probability of a false negative (assuming that $B d$ had been present at a 244 prevalence of 5\%). The probability of a false negative was 0.007 for 1952-1968, 0.09 for 1964 245 and 0.12 for 1968.

247 Current Bd and Bsal prevalence in caves of Mexico

248 A total of 29 skin swabs of salamanders and frogs were collected from cave study sites; we did 249 not observe dead amphibians or individuals with skin lesions at any site. Chiropterotriton 250 magnipes was found in two of the 15 sites surveyed, with both extant populations representing 251 new localities; no individuals were found in sites with historical records of the species. Of the six

252 C. magnipes we found at El Coni, Hidalgo, we sampled a minimum of five different individuals 
253 based on age and sex of the specimens and of the nine C. magnipes from La Trinidad, we 254 sampled a minimum of six different individuals (Table 1). We detected $B d$ at three of the six 255 sites where we found amphibians (Table 3) with 27.6\% (8/29) of individuals tested being $B d$ 256 positive. Both of the sites we surveyed with extant populations of C. magnipes (El Coni, Hidalgo 257 and La Trinidad, San Luis Potosí) tested positive for $B d$, with a prevalence of $29.1 \%(7 / 24)$ and a 258 low to moderate infection intensity (6-2618 GE) across species at El Coni, and a lower 259 prevalence (11\%, 2/9 samples) and relatively low infection intensity (312-472 GE) at La 260 Trinidad. ITS copy number can vary between $B d$ strains, affecting prevalence and infection 261 intensity estimates from qPCR (Longo et al. 2013, Rebollar et al. 2017). Because we did not 262 have a $B d$ isolate from these populations to quantify ITS copy number, estimates of GE should 263 be regarded as approximate. $B d$-positive individuals of $C$. magnipes were detected at both sites 264 (Table 3). Other salamander species found in caves with extant populations of C. magnipes 265 tested positive for $B d$, with 1/3 Chiropterotriton mosaueri and 2/6 Aquiloeurycea sp. testing 266 positive. A single frog (Craugastor decoratus) from a cave where no C. magnipes were found 267 also tested positive for $B d$. All individuals that tested positive for $B d$ were adults or subadults. Of 268 the 14 salamanders included in our sample, none tested positive for Bsal.

269

270 Bd genotyping

271 Genotyping was successful for only one of the two modern $B d$-positive samples of C. magnipes 272 from El Coni, Hidalgo and matched the Global Panzootic Linage subclade 1 (Bd-GPL-1). In our 273 phylogenetic analyses we found that the sample successfully sequenced was most closely related 274 to another sample collected from Chiapas, Mexico and published previously (Byrne et al. 2019) 
275 (Figure $\mathrm{S} 1$ ). None of the six historical $B d$-positive samples produced any usable sequence data 276 for genotyping.

277

278 Discussion

279 Detection of $B d$ in extant populations of $C$. magnipes, together with its apparent arrival shortly 280 before observed population declines based on museum samples, point to a role of $B d$ in the 281 declines of this species. Other aspects of our results, including relatively low $B d$ prevalence 282 during declines, make the overall picture involving the role of $B d$ in the decline of $C$. magnipes 283 less clear. While we detected Bd-GPL in the one extant sample we successfully genotyped, our 284 failure to successfully genotype historical positives complicates interpretation of our historical $285 B d$ results.

286 Our retrospective historical survey of $B d$ prevalence in populations of $C$. magnipes

287 revealed that $B d$ was not detected in a large sample size from 1952-1968, during a period of high 288 salamander abundance, and was detected shortly before and during the subsequent period of 289 decline in salamander abundance. The estimate of $B d$ prevalence for the final year with a 290 relatively large sample of specimens $(1975,9.1 \%$ [95\% CI 3-24\%]) is higher than in previous 291 years following first detection (0-2.2\% prevalence, upper limit of $95 \%$ CI 11\%). These results 292 are consistent with the arrival of a novel pathogen to populations of a naïve host, as outlined in 293 the epidemic wave hypothesis (Lips et al. 2008). Other aspects of our results are less consistent 294 with a $B d$-associated decline, however. Following first detection, the prevalence of $B d$ remained 295 low to moderate in our sample (1.2-50\% between 1969 and 1982), and $B d$ was not detected our 296 relatively small samples from 1971 (10 specimens) and 1979 (3 specimens). Furthermore, the $29795 \%$ confidence intervals for $B d$ prevalence overlap for all years the fungus was detected. 
298 Despite our near-complete sampling of available museum specimens, the small sample size for 299 all years following 1975 (resulting directly from declines in salamander abundance) make it 300 difficult to infer trends in $B d$ prevalence with confidence.

301 Our contemporary surveys for $B d$ show that the fungus is present in both sites with extant 302 C. magnipes populations, although not at especially high prevalence (Table 3). Individuals of $C$. 303 magnipes, (2/6 at El Coni and 2/9 at La Trinidad) tested positive for $B d$ and two of the other 304 three species that we encountered at El Coni had $B d$-positive individuals. Only 305 Eleutherodactylus cystignathoides from El Coni tested negative for $B d$ for all samples (although 306 we collected only two samples of this species), and only one individual of any other species (a 307 Craugastor decoratus) tested positive from the four other caves where we detected amphibians. 308 Overall, the prevalence of $B d$ in our contemporary sample was relatively low $(27.6 \%)$, roughly 309 comparable to that of Australian amphibians in enzootic stages of $B d$ infection surveyed $>8$ years 310 after declines (15-28\%) (Retallick et al. 2004; Woodhams and Alford 2005; Kriger and Hero 311 2006). The one contemporary sample that we were able to genotype was assigned to the Global 312 Panzootic Lineage, which has been implicated in amphibian declines in Latin America and 313 worldwide (Rosenblum et al. 2013). This does not necessarily mean that only this lineage is 314 present at these sites, as coexistence of Bd-GPL and other $B d$ strains has been shown at multiple 315 sites using molecular data (Byrne et al. 2019). Genotyping of larger sample of Bd-positive 316 amphibians from the region would be needed to understand whether Bd-GPL is the only strain 317 present, and should be undertaken.

318 The failure of the $B d$ genotyping approach for our historical $B d$-positive samples means 319 that we cannot state with certainty that these older samples were infected with Bd-GPL. One of 320 our current positive samples was assigned to Bd-GPL, and no other lineage of $B d$ has been 
321 reported from Mexico to date (O'Hanlon et al. 2018; Byrne et al. 2019). It is thus logical to

322 consider that the lineage of $B d$ that we detected in 1969 may also have been Bd-GPL, but 323 genotyping of additional contemporary $B d$ samples could reveal the presence of additional

324 lineages, complicating this interpretation. Genotyping of our historic samples may have failed 325 due to DNA damage from formalin fixation, possibly combined with a low amount of starting 326 material as a result of low infection intensity. If specimens were fixed in formalin for a relatively 327 long period of time (days) or stored in formalin prior to transfer to ethanol, this might decrease 328 the probability of successfully amplifying fungal DNA from these specimens. Unfortunately, 329 information on formalin fixation time is not available for the museum samples we attempted to genotype. The genotyping protocol has worked successfully with other museum samples (Byrne et al. 2019) but may need to be adapted to better amplify $B d$ from historical formalin-preserved samples. Genotyping additional historical positive samples will be useful to determine if preservation time or other factors impact the efficacy of the method in museum samples. The qPCR assay we used has been shown to be sensitive to detecting Bd in formalinfixed specimens that are decades old (Cheng et al. 2012; Adams et al. 2017). DNA damage 336 (either from formalin or due to long preservation time) or low infection intensity could result in 337 false negatives using this method, however, particularly in the oldest specimens. Because of this, 338 we cannot exclude the possibility of false negative detections prior to the first $B d$-positive 339 specimen in 1969. Validation of historical $B d$-positive and $B d$-negative samples from qPCR

340 through histological examination would strengthen the case for arrival of $B d$ at the end of the 341 1960s. It is also possible that some $B d$-positive results from our qPCR assay resulted from cross 342 contamination between specimens kept in the same jar in museums. The fact that most of the

343 historical specimens in our sample tested negative for $B d$, despite many being stored in jars with 
$344 B d$-positive specimens, argues against this being a major problem, but it cannot be discounted

345 with the sampling methodology we used.

The results of our field surveys across the range of $C$. magnipes complement $B d$ detection

347

348

349

350

351

352

353

354

355

356

357

358

359

360

361

362

363

364

365

data in revealing apparent population extirpation at historical sites and low abundance in extant populations. We visited some sites only once during our survey and, given the low numbers of salamanders seen in extant populations and the fact that we $\operatorname{did}$ not always $\operatorname{detect} C$. magnipes where it remains present, it is possible that salamanders are still present at other historical sites but went undetected. Prior to this study, however, we (and others) have made multiple visits to Cueva de La Iglesia and Cueva de Potrerillos (the type locality of the species) without detecting C. magnipes. Very few individuals of C. magnipes were found in the two caves we surveyed with extant populations over the course of multiple visits. This stands in marked contrast to the dozens of individuals collected at historic sites before declines (Table 2). The low number of salamanders detected at these two sites could either be the result of ongoing small population size following declines due to epizootic $B d$ infection (or other causes) or a reflection that they naturally occur at low abundance at these sites. We never found more than five individuals on repeated visits to both sites from 2010 to the present, making it unlikely that the low number of individuals detected is a sampling artifact. The lack of precise estimates of C. magnipes abundance at historical sites (because not all individuals seen were necessarily collected) makes a direct comparison with previous abundance of the species impossible, but it is notable that neither of the contemporary population seems to reach the abundance reflected in museum samples from historic sites.

We note that almost all known localities of $C$. magnipes are along roads or near towns, where detection by local people or scientists is most likely; the karstic geology of the region 
367 means that there are likely hundreds or thousands of other small caves within more remote

368 portions of the species' range that have not yet been searched. Furthermore, many parts of the

369 caves we did explore cannot be accessed easily (at least not without professional equipment) and

370 cave systems could be connected by subterranean passages, providing more habitat than is

371 currently known. In most cases where we did find C. magnipes, they were relatively close to the

372 mouths of caves, but we cannot discount the possibility that we were not able to detect

373 salamanders in inaccessible or deeper portions of caves.

374

Taken together, these results suggest that the invasion of $B d$ may have played a role in the

375 decline and apparent disappearance of $C$. magnipes from most known sites. Our data show that

$376 B d$ was most likely absent from these populations prior to 1969 . After that, it likely arrived

377 several years before observed declines in salamander abundance, similar to declines in other

378 Neotropical salamanders that were putatively caused by $B d$ (Cheng et al. 2011). Indeed, the lag

379 time between first $B d$ detection and population declines and increases in prevalence of $B d$ seen in

380 our results parallels that described in Cheng et al. (2011) from other sites in Mexico, although

381 direct evidence linking $B d$ and declines at those sites is lacking. The fact that extant populations

382 have low abundance of $C$. magnipes and are positive for $B d$ raises the possibility that infection at

383 this site may have moved to an enzootic phase where $B d$ coexists with its host without causing

384 mass mortality (Briggs et al. 2010).

385 While we document the arrival of $B d$ in populations of $C$. magnipes shortly before

386 declines in host abundance, we lack data on the susceptibility of $C$. magnipes to $B d$ infection.

387 Because C. magnipes is Critically Endangered and protected by Mexican law (Norma Mexicana

388 059-SEMARNAT-2010), it is not possible to collect individuals to conduct susceptibility trials

389 for $B d$. If $C$. magnipes is indeed highly susceptible to $B d$ infection, rapid elimination of infected 
390 individuals from the population could explain both the relatively low prevalence of $B d$ and the 391 small number of individuals observed. We cannot discount this possibility but we did not note 392 any apparent signs of infection (loose skin, lethargy) when sampling individuals that later tested 393 positive for $B d$. Lacking information on susceptibility means that a direct link between $B d$ 394 infection and salamander mortality cannot be established. Nevertheless, our data fit into a wider 395 context of $B d$ invasion followed by collapse of host species and suggest that Bd-GPL may be 396 implicated in the decline of C. magnipes.

While some of the caves surveyed had been damaged or were highly disturbed, most still 398 appeared to contain appropriate conditions for salamanders, including wet surfaces, cracks, and invertebrate food sources. At other sites, however, habitat degradation may have played a role in 400 observed declines. The type locality of C. magnipes at Potrerillos has little remaining vegetation 401 around the cave mouth, likely affecting its microclimatic conditions to some extent. If $B d$ was 402 responsible for declines of C. magnipes, it remains possible that declines in habitat quality 403 played a role as well (separate from or synergistically with $B d$ ). It is also possible that over404 collecting at two sites (Potrerillos and Cueva de la Iglesia, Ahuacatlán), contributed to the 405 decline of the species at these two sites. Large series of specimens were taken from these two 406 sites between 1964 and 1975, possibly reducing abundance below the point where reproduction 407 was sufficient to offset loss of individuals to museum collections. Chiropterotriton magnipes 408 might be especially susceptible to over-collection, given that it occurs in spatially concentrated 409 cave habitats. Over-collecting could not, however, account for the fact that the two extant sites 410 surveyed (both recently discovered localities) have low abundance of individuals, despite never 411 having had large series of specimens collected. 

in Mesoamerica by extending the detection of $B d$ back to 1969 in Mexico and to species that 414 occur in specialized habitats such as caves. In Mexico, the previous earliest known $B d$ positive 415 specimen came from Cerro Chicahuaxtla, Veracruz, approximately $345 \mathrm{~km}$ from our positive sample from 1969 (Cheng et al. 2011). Chiropterotriton chico collected in 1974 from El Chico

417 National Park in Hidalgo, $130 \mathrm{~km}$ south of our $1969 B d$-positive sample, represents the nearest 418 early $B d$ detection to the range of $C$. magnipes. The detection of $B d$ in $C$. magnipes to the north 419 of previous historical positive samples is consistent with the hypothesis that Bd-GPL invaded 420 from the north to the southeast through naïve amphibian populations (Rachowicz et al. 2005;

421 Rachowicz et al. 2006) in Mesoamerica. However, recent detection of $B d$-positive amphibians 422 from 1964 in Costa Rica (De Leon et al. 2019), as well as phylogenetic evidence for the presence 423 of multiple lineages of $B d$ in other regions of Latin America (Byrne et al. 2019), suggest that $B d$ 424 likely has a more complex history in the Americas than a simple north-to-south invasion.

425 Successful genotyping of historical $B d$ positives from Mexico would clarify whether they 426 resulted from a wave-like invasion of Bd-GPL or reflect the presence of a different lineage with 427 a longer history in the region. Inherent properties of declining populations (low abundance 428 during and after declines, inability to or restrictions on sampling the few remaining individuals) mean that the role of $B d$ in past declines of $C$. magnipes may never be definitively shown, but 430 our results point towards a role for $B d$ in these declines.

431 The current conservation status of $C$. magnipes is challenging, given that nearly all 432 known populations appear to be extirpated and both known extant populations are infected with $433 B d$. The fact that individuals in both populations appear healthy and have maintained a relatively 434 constant (if low) abundance since their discovery suggests that they are not in a state of 
435 continuing decline, but it is also possible that they could be negatively affected by $B d$. In order to

436 truly test this idea, dynamic data showing the host/pathogen dynamics through time are needed

437 (Briggs et al. 2010; Vredenburg et al. 2010). If these populations are currently in an enzootic

438 state of $B d$ infection, monitoring may be the best available option. Recent efforts to extirpate $B d$

439 in wild populations of amphibians via fungicide treatment (Bosch et al. 2015) were not

440 successful in the long term. We suggest that monitoring both pathogen and host in this

441 population of salamanders be implemented immediately to document changes in salamander

442 abundance and infection intensity, which can be indicative of host survival (Vredenburg et al.

443 2010; Lannoo et al. 2011). Clearly, the cave habitats must be protected from excessive human

444 visitation and other human impacts.

445

446 Conclusions

447 Our results show that $B d$ may have contributed to the decline of one of the most enigmatic and

448 unusual amphibians in the Neotropics. $B d$ appears to have arrived in 1969 after being previously

449 absent, and its arrival occurred shortly before declines in abundance. Our genotyping results

450 show that Bd-GPL, the lineage responsible for most amphibian declines, is currently present in

451 populations of $C$. magnipes, but the failure to genotype historical samples means that we cannot

452 definitively say that Bd-GPL was present in these populations in past decades. The fact that two

453 known populations persist despite being infected with $B d$, albeit at low abundance, suggests that

454 populations may be able to coexist with the pathogen (Knapp et al. 2016) allowing them to

455 persist into the future. At present, monitoring both host and pathogen may be the best available

456 conservation option for this species.

457

Peer] reviewing PDF | (2020:05:48948:1:1:NEW 21 Jul 2020) 


\section{Acknowledgements}

459 We thank Greg Schneider and Dan Rabosky (UMMZ), Toby Hibbits (TCWC), David Wake and

460 Carol Spencer (MVZ), James Hanken (MCZ), Alan Resetar (FMNH), and Chris Austin (LSU)

461 for access to museum collections and help with swab collection. Hassan Sulaeman provided

462 critical help in the lab at SFSU, and Alexander Catenazzi kindly ran the qPCR assay for Bsal.

463 Emanuel Martínez-Ugalde, Jorge Alejandro López Torres, María Guadalupe Segovia Ramírez,

464 and Louis Paul Decena Segarra provided help in the field. Chris Grünwald provided the location 465 of the La Trinidad population of C. magnipes.

466

467 References

468 Adams A., A. P. Pessier, and C. J. Briggs. 2017. Rapid extirpation of a North American frog

469 coincides with an increase in fungal pathogen prevalence: Historical analysis and

$470 \quad$ implications for reintroduction. Ecology and Evolution 7:10216-10232.

471 AmphibiaWeb. 2020. Information on Amphibian Biology and Conservation. Available at

$472 \quad$ www.amphibiaweb.org (accessed 13 May 2020).

473 Berger L., R. Speare, P. Daszak, D. E. Green, A. A. Cunningham, C. L. Goggin, R. Slocombe,

474 M. A. Ragan, A. D. Hyatt, K. R. McDonald, H. B. Hines, K. R. Lips, G. Marantelli, and H.

475 Parkes. 1998. Chytridiomycosis causes amphibian mortality associated with population

476 declines in the rain forests of Australia and Central America. Proceedings of the National

477 Academy of Sciences of the United States of America 95:9031-9036.

478 Blooi M., F. Pasmans, J. E. Longcore, A. Spitzen-van der Sluijs, F. Vercammen, and A. Martel.

479 2013. Duplex real-time PCR for rapid simultaneous detection of Batrachochytrium 
480

481

482

483

484

485

486

487

488

489

490

491

492

493

494

495

496

497

498

499

500

501

502

dendrobatidis and Batrachochytrium salamandrivorans in amphibian samples. Journal of Clinical Microbiology 51:4173-4177.

Bosch J., E. Sanchez-Tome, A. Fernandez-Loras, J. A. Oliver, M. C. Fisher, and T. W. Garner. 2015. Successful elimination of a lethal wildlife infectious disease in nature. Biology Letters $11: 10.1098 / \mathrm{rsbl} .2015 .0874$

Briggs C. J., R. A. Knapp, and V. T. Vredenburg. 2010. Enzootic and epizootic dynamics of the chytrid fungal pathogen of amphibians. Proceedings of the National Academy of Sciences of the United States of America 107:9695-9700.

Burrowes P. A., and I. De la Riva. 2017. Unraveling the historical prevalence of the invasive chytrid fungus in the Bolivian Andes: implications in recent amphibian declines. Biological Invasions 19:1781-1794.

Burrowes P. A., T. Y. James, T. S. Jenkinson, and I. De la Riva. 2020. Genetic analysis of postepizootic amphibian chytrid strains in Bolivia: Adding a piece to the puzzle. Transboundary and Emerging Diseases, in press.

Byrne A. Q., A. P. Rothstein, T. J. Poorten, J. Erens, M. L. Settles, and E. B. Rosenblum. 2017. Unlocking the story in the swab: a new genotyping assay for the amphibian chytrid fungus Batrachochytrium dendrobatidis. Molecular Ecology Resources 17:1283-1292.

Byrne A. Q., V. T. Vredenburg, A. Martel, F. Pasmans, R. C. Bell, D. C. Blackburn, M. C. Bletz, J. Bosch, C. J. Briggs, R. M. Brown, A. Catenazzi, M. Familiar Lopez, R. FigueroaValenzuela, S. L. Ghose, J. R. Jaeger, A. J. Jani, M. Jirku, R. A. Knapp, A. Munoz, D. M. Portik, C. L. Richards-Zawacki, H. Rockney, S. M. Rovito, T. Stark, H. Sulaeman, N. T. Tao, J. Voyles, A. W. Waddle, Z. Yuan, and E. B. Rosenblum. 2019. Cryptic diversity of a widespread global pathogen reveals expanded threats to amphibian conservation. 
503

504

505

506

507

508

509

510

511

512

513

514

515

516

517

518

519

520

521

522

523

524

525

Proceedings of the National Academy of Sciences of the United States of America $116: 20382-20387$.

Catenazzi A., E. Lehr, L. O. Rodriguez, and V. T. Vredenburg. 2011. Batrachochytrium dendrobatidis and the collapse of anuran species richness and abundance in the Upper Manu National Park, Southeastern Peru. Conservation Biology 25:382-391.

Cheng T. L., S. M. Rovito, D. B. Wake, and V. T. Vredenburg. 2011. Coincident mass extirpation of neotropical amphibians with the emergence of the infectious fungal pathogen Batrachochytrium dendrobatidis. Proceedings of the National Academy of Sciences of the United States of America 108:9502-9507.

De Leon M. E., V. T. Vredenburg, and J. Piovia-Scott. 2017. Recent rmergence of a chytrid fungal pathogen in California Cascades Frogs (Rana cascadae). Ecohealth 14:155-161.

De Leon M. E., H. Zumbado-Ulate, A. García-Rodríguez, G. Alvarado, H. Sulaeman, F. Bolaños, and V. T. Vredenburg. 2019. Batrachochytrium dendrobatidis infection in amphibians predates first known epizootic in Costa Rica. PLoS One 14:e0208969.

Edgar R. C. 2004. MUSCLE: a multiple sequence alignment method with reduced time and space complexity. BMC Bioinformatics 5:1-19.

Farrer R. A., L. A. Weinert, J. Bielby, T. W. Garner, F. Balloux, F. Clare, J. Bosch, A. A. Cunningham, C. Weldon, L. H. du Preez, L. Anderson, S. L. Pond, R. Shahar-Golan, D. A. Henk, and M. C. Fisher. 2011. Multiple emergences of genetically diverse amphibianinfecting chytrids include a globalized hypervirulent recombinant lineage. Proceedings of the National Academy of Sciences of the United States of America 108:18732-18736.

Hyatt A. D., D. G. Boyle, V. Olsen, D. B. Boyle, L. Berger, D. Obendorf, A. Dalton, K. Kriger, M. Heros, H. Hines, R. Phillott, R. Campbell, G. Marantelli, F. Gleason, and A. Coiling. 
526

527

528

529

530

531

532

533

534

535

536

537

538

539

540

541

542

543

544

545

546

547

548

2007. Diagnostic assays and sampling protocols for the detection of Batrachochytrium dendrobatidis. Diseases of Aquatic Organisms 73:175-192.

Knapp R. A., G. M. Fellers, P. M. Kleeman, D. A. Miller, V. T. Vredenburg, E. B. Rosenblum, and C. J. Briggs. 2016. Large-scale recovery of an endangered amphibian despite ongoing exposure to multiple stressors. Proceedings of the National Academy of Sciences of the United States of America 113:11889-11894.

Kriger K., and J. M. Hero. 2006. Large-scale seasonal variation in the prevalence and severity of chytridiomycosis. Journal of Zoology (London) 271:352-359.

La Marca E., K. R. Lips, S. Lotters, R. Puschendorf, R. Ibañez, J. V. Rueda-Almonacid, R. Schulte, C. Marty, F. Castro, J. Manzanilla-Puppo, J. E. García-Pérez, F. Bolaños, G. Chaves, J. A. Pounds, E. Toral, and B. E. Young. 2005. Catastrophic population declines and extinctions in neotropical harlequin frogs (Bufonidae : Atelopus). Biotropica 37:190201.

Lannoo M. J., C. Petersen, R. E. Lovich, P. Nanjappa, C. Phillips, J. C. Mitchell, and I. Macallister. 2011. Do frogs get their kicks on Route 66? Continental U.S. transect reveals spatial and temporal patterns of Batrachochytrium dendrobatidis infection. PLoS One 6:e22211.

Lips K. R. 1998. Decline of a tropical montane amphibian fauna. Conservation Biology 12:106117.

Lips K. R. 2016. Overview of chytrid emergence and impacts on amphibians. Philosophical Transactions of the Royal Society B-Biological Sciences 371:20150465.

Lips K. R., F. Brem, R. Brenes, J. D. Reeve, R. A. Alford, J. Voyles, C. Carey, L. Livo, A. P. Pessier, and J. P. Collins. 2006. Emerging infectious disease and the loss of biodiversity in a 
549

550

551

552

553

554

555

556

557

558

559

560

561

562

563

564

565

566

567

568

569

570

571

Neotropical amphibian community. Proceedings of the National Academy of Sciences of the United States of America 103:3165-3170.

Lips K. R., J. Diffendorfer, M. J. R. III, and M. W. Sears. 2008. Riding the wave: reconciling the roles of disease and climate change in amphibian declines. PLoS Biology 6:441-454.

Longo A. V., D. Rodriguez, L. D. da Silva, L. F. Toledo, C. Mendoza Almeralla, P. A.

Burrowes, and K. R. Zamudio. 2013. ITS1 copy number varies among Batrachochytrium dendrobatidis strains: implications for qPCR estimates of pathogen load from field-collected amphibian skin swabs. PLoS ONE 8:e59499

Longcore J. E., A. P. Pessier, and D. K. Nichols. 1999. Batrachochytrium dendrobatidis gen et sp nov, a chytrid pathogenic to amphibians. Mycologia 91:219-227.

Magoc T., and S. L. Salzberg. 2011. FLASH: fast length adjustment of short reads to improve genome assemblies. Bioinformatics 27:2957-2963.

Mendelson J. R. III., M. E. B. Jones, A. P. Pessier, G. Toledo, E. H. Kabay, and J. A. Campbell. 2014. On the timing of an epidemic of amphibian chytridiomycosis in the highlands of Guatemala. South American Journal of Herpetology 9:151-153.

O'Hanlon S. J., A. Rieux, R. A. Farrer, G. M. Rosa, B. Waldman, A. Bataille, T. A. Kosch, K. A. Murray, B. Brankovics, M. Fumagalli, M. D. Martin, N. Wales, M. Alvarado-Rybak, K. A. Bates, L. Berger, S. Boll, L. Brookes, F. Clare, E. A. Courtois, A. A. Cunningham, T. M. Doherty-Bone, P. Ghosh, D. J. Gower, W. E. Hintz, J. Hoglund, T. S. Jenkinson, C. F. Lin, A. Laurila, A. Loyau, A. Martel, S. Meurling, C. Miaud, P. Minting, F. Pasmans, D. S. Schmeller, B. R. Schmidt, J. M. G. Shelton, L. F. Skerratt, F. Smith, C. Soto-Azat, M. Spagnoletti, G. Tessa, L. F. Toledo, A. Valenzuela-Sanchez, R. Verster, J. Voros, R. J. Webb, C. Wierzbicki, E. Wombwell, K. R. Zamudio, D. M. Aanensen, T. Y. James, M. T. 
572

573

574

575

576

577

578

579

580

581

582

583

584

585

586

587

588

589

590

591

592

593

594

P. Gilbert, C. Weldon, J. Bosch, F. Balloux, T. W. J. Garner, and M. C. Fisher. 2018. Recent Asian origin of chytrid fungi causing global amphibian declines. Science 360:621-627.

Parra-Olea G., D. B. Wake, and J. Hanken. 2008. Chiropterotriton magnipes. IUCN Red List. Available at www.iucnredlist.org (accessed 13 May 2020).

R Development Core Team. 2015. R: a language and environment for statistical computing. R Foundation for Statistical Computing, Vienna, Austria.

Rabb G. B. 1965. A new salamander of the genus Chiropterotriton (Caudata: Plethodontidae) from Mexico. Breviora 235:1-8.

Rachowicz L. J., R. A. Knapp, J. A. Morgan, M. J. Stice, V. T. Vredenburg, J. M. Parker, and C. J. Briggs. 2006. Emerging infectious disease as a proximate cause of amphibian mass mortality. Ecology 87:1671-1683.

Rachowicz L. J., J. M. Hero, R. A. Alford, J. W. Taylor, J. A. T. Morgan, V. T. Vredenburg, J. P. Collins, and C. J. Briggs. 2005. The novel and endemic pathogen hypotheses: competing explanations for the origin of emerging infectious diseases of wildlife. Conservation Biology $19: 1441-1448$.

Rebollar E. A., D. C. Woodhams, B. LaBumbard, J. Kielgast, and R. N. Harris. 2017. Prevalence and pathogen load estimates for the fungus Batrachochytrium dendrobatidis are impacted by ITS DNA copy number variation. Diseases of Aquatic Organisms 123:213-226.

Retallick R. W. R., H. McCallum, and R. Speare. 2004. Endemic infection of the amphibian chytrid fungus in a frog community post-decline. PLoS Biology 2:1965-1971.

Rosenblum E. B., T. Y. James, K. R. Zamudio, T. J. Poorten, D. Ilut, D. Rodriguez, J. M. Eastman, K. Richards-Hrdlicka, S. Joneson, T. S. Jenkinson, J. E. Longcore, G. Parra Olea, L. F. Toledo, M. L. Arellano, E. M. Medina, S. Restrepo, S. V. Flechas, L. Berger, C. J. 
595

596

597

598

599

600

601

602

603

604

605

606

607

608

609

610

611

612

613

614

615

Briggs, and J. E. Stajich. 2013. Complex history of the amphibian-killing chytrid fungus revealed with genome resequencing data. Proceedings of the National Academy of Sciences of the United States of America 110:9385-9390.

Rovito S. M., G. Parra-Olea, C. R. Vásquez-Almazán, T. J. Papenfuss, and D. B. Wake. 2009. Dramatic declines in neotropical salamander populations are an important part of the global amphibian crisis. Proceedings of the National Academy of Sciences of the United States of America 106:3231-3236.

Scheele B. C., F. Pasmans, L. F. Skerratt, L. Berger, A. Martel, W. Beukema, A. A. Acevedo, P. A. Burrowes, T. Carvalho, A. Catenazzi, I. De la Riva, M. C. Fisher, S. V. Flechas, C. N. Foster, P. Frias-Alvarez, T. W. J. Garner, B. Gratwicke, J. M. Guayasamin, M. Hirschfeld, J. E. Kolby, T. A. Kosch, E. La Marca, D. B. Lindenmayer, K. R. Lips, A. V. Longo, R. Maneyro, C. A. McDonald, J. Mendelson 3rd, P. Palacios-Rodriguez, G. Parra-Olea, C. L. Richards-Zawacki, M. O. Rodel, S. M. Rovito, C. Soto-Azat, L. F. Toledo, J. Voyles, C. Weldon, S. M. Whitfield, M. Wilkinson, K. R. Zamudio, and S. Canessa. 2019. Amphibian fungal panzootic causes catastrophic and ongoing loss of biodiversity. Science 363:14591463.

Stamatakis A. 2014. RAxML version 8: a tool for phylogenetic analysis and post-analysis of large phylogenies. Bioinformatics 30:1312-1313.

Talley B. L., C. Muletz, R. Fleischer, V. T. Vredenburg, and K. R. Lips. 2015. Century of Batrachochytrium dendrobatidis in Illinois Amphibians (1888-1989). Biological Conservation 182:254-261.

PeerJ reviewing PDF | (2020:05:48948:1:1:NEW 21 Jul 2020) 
616 Vredenburg V. T., R. A. Knapp, T. S. Tunstall, and C. J. Briggs. 2010. Dynamics of an emerging 617 disease drive large-scale amphibian population extinctions. Proceedings of the National 618 Academy of Sciences of the United States of America 107:9689-9694.

619 Vredenburg V. T., S. V. G. McNally, H. Sulaeman, H. M. Butler, T. Yap, M. S. Koo, D. S. 620 Schmeller, C. Dodge, T. Cheng, G. Lau, and C. J. Briggs. 2019. Pathogen invasion history 621 elucidates contemporary host pathogen dynamics. PLoS One 14:e0219981.

622 Wake D. B., and V. T. Vredenburg. 2008. Colloquium paper: are we in the midst of the sixth 623 mass extinction? A view from the world of amphibians. Proceedings of the National 624 Academy of Sciences of the United States of America 105 Suppl 1:11466-11473.

625 Woodhams D. C., and R. A. Alford. 2005. Ecology of chytridiomycosis in rainforest stream frog 626 assemblages of tropical Queensland. Conservation Biology 19:1449-1459.

627 Young B. E., K. R. Lips, J. K. Reaser, R. Ibanez, A. W. Salas, J. R. Cedeno, L. A. Coloma, S.

628 Ron, E. La Marca, J. R. Meyer, A. Munoz, F. Bolanos, G. Chaves, and D. Romo. 2001. 629 Population declines and priorities for amphibian conservation in Latin America. $630 \quad$ Conservation Biology 15:1213-1223.

631 Zhang C., M. Rabiee, E. Sayyari, and S. Mirarab. 2018. ASTRAL-III: polynomial time species 632 tree reconstruction from partially resolved gene trees. BMC Bioinformatics 19:153-018633 2129-y. 


\section{Table $\mathbf{1}$ (on next page)}

Locality information and number of individuals detected for all live Chiropterotriton magnipes tested for $B d$.

Locality information, geographic coordinates, and number of individuals of $C$. magnipes detected for caves where searches for $C$. magnipes were conducted. Locality numbers correspond to those in Figure 1. Locality names with an asterisk are historical localities that are represented in museum collections. Number of $C$. magnipes detected is greater than number of individuals sampled for Bd in some cases because not all salamanders detected were accessible for sampling. For C. magnipes detected, letters in parentheses indicate adult females (F), adult males (M), juveniles (J), or individuals not captured (N). Subscript $C$ refers to voucher specimens collected. Geographic coordinates provided to only two decimal places to protect sensitive cave habitat. 
1

\begin{tabular}{|c|c|c|c|c|c|c|}
\hline $\begin{array}{l}\text { Locality } \\
\text { number }\end{array}$ & Locality name & State & Latitude & Longitude & Search date & $\begin{array}{l}\text { Number } \\
\text { and age } \\
\text { class/sex of } \\
C \text {. } \\
\text { magnipes } \\
\text { detected }\end{array}$ \\
\hline
\end{tabular}

\begin{tabular}{|c|c|c|c|c|c|c|}
\hline 1 & $\begin{array}{l}\text { Cueva de los } \\
\text { Cuartos }\end{array}$ & Qro & 21.34 & -99.15 & 8 July 2017 & 0 \\
\hline 2 & $\begin{array}{l}\text { Cueva de los } \\
\text { Lirios }\end{array}$ & Qro & 21.39 & -99.14 & 8 July 2017 & 0 \\
\hline 3 & $\begin{array}{l}\text { Lagunitas de } \\
\text { San Diego }\end{array}$ & Qro & 21.37 & -99.14 & 25 Mar 2017 & 0 \\
\hline 4 & $\begin{array}{l}3.4 \mathrm{~km} \mathrm{~W} \text { of El } \\
\text { Madroño, Qro* }\end{array}$ & Qro & 21.26 & -99.18 & 14 Sept 2017 & 0 \\
\hline 5 & $\begin{array}{l}\text { Cueva de la } \\
\text { Araña, El } \\
\text { Madroño* }\end{array}$ & Qro & 21.27 & -99.16 & $\begin{array}{l}24 \text { Mar 2017, } 6 \text { July } \\
2017,7 \text { July } 2017 \text {, } \\
25 \text { Aug } 2017,10 \\
\text { Oct } 2018\end{array}$ & 0 \\
\hline $6 a$ & $\begin{array}{l}\text { Llano de los } \\
\text { Caballos }\end{array}$ & SLP & 21.40 & -99.08 & 6 July 2017 & 0 \\
\hline $6 \mathrm{~b}$ & $\begin{array}{l}\text { Cueva de los } \\
\text { Cabritos }\end{array}$ & SLP & 21.40 & -99.08 & 6 July 2017 & 0 \\
\hline 7 & La Trinidad & SLP & 21.40 & -99.07 & $\begin{array}{l}6 \text { July } 2017,7 \text { July } \\
2017,1 \text { Aug 2018, } \\
24 \text { Aug 2017, } 18 \\
\text { Oct } 2018\end{array}$ & $\begin{array}{l}3\left(\mathrm{~F}_{\mathrm{C}}, \mathrm{N},\right. \\
\mathrm{N}), 4(\mathrm{~F}, \mathrm{~F}, \\
\mathrm{J}, \mathrm{J}), 1(\mathrm{M}), \\
1(\mathrm{~F}), 2(\mathrm{M}, \\
\mathrm{F})\end{array}$ \\
\hline 8 & $\begin{array}{l}\text { Cueva Llano } \\
\text { Chico }\end{array}$ & SLP & 21.38 & -99.10 & 2 Aug 2017 & 0 \\
\hline 9 & $\begin{array}{l}\text { Cueva de las } \\
\text { Golondrinas, } \\
\text { San Antonio }\end{array}$ & SLP & 21.36 & -99.01 & 26 Mar 2017 & 0 \\
\hline 10 & $\begin{array}{l}\text { Cueva de la } \\
\text { Barranca }\end{array}$ & SLP & 21.33 & -99.05 & $\begin{array}{l}26 \text { Mar 2017, } 7 \text { July } \\
2017\end{array}$ & 0 \\
\hline
\end{tabular}


$11 \quad$ Cueva de la $\quad$ SLP $21.32 \quad-99.05 \quad 23$ Mar 2017 $\quad 0$

Iglesia,

Ahuacatlán*

$12 \quad$ Cueva de $\quad$ SLP $21.31 \quad-99.07 \quad 23$ Mar 2017, 6 July 0

Potrerillos 2017

(type locality)

13 Cueva El Coni, Hgo $20.89 \quad-99.23 \quad 21$ Mar 2017, $12 \quad 1(\mathrm{M}), 1$

Durango June 2017, 31 July $\left(\mathrm{F}_{\mathrm{C}}\right), 3(\mathrm{~F}$, 2017, 23 Aug 2017, F, F), 1

8 Oct 2018,17 Oct $\quad(\mathrm{M}), 0,0$ 2018 


\section{Table 2 (on next page)}

Results of qPCR assay for Bd in historical museum samples by year sampled.

Bold font indicates samples that tested positive for Bd. Numbers in parentheses after locality name indicate number of museum specimens swabbed from the locality from each year. Various localities within a few km west of El Lobo and El Madroño, Qro are listed as “W of El Madroño". 
1

\begin{tabular}{|c|c|c|c|c|}
\hline $\begin{array}{l}\text { Year of } \\
\text { collection }\end{array}$ & $\begin{array}{l}\text { Localities } \\
\text { sampled (No. } \\
\text { sampled) }\end{array}$ & No. sampled & $\begin{array}{l}\text { No. positives } \\
\text { for } \mathrm{Bd}\end{array}$ & $\begin{array}{l}\% \text { Bd prevalence (95\% Clopper- } \\
\text { Pearson Confidence Interval) }\end{array}$ \\
\hline 1952 & $\begin{array}{l}\text { W of El } \\
\text { Madroño, Qro } \\
\text { (1), Cueva de } \\
\text { Potrerillos, SLP } \\
\text { (2) }\end{array}$ & 3 & 0 & $0(0-60)$ \\
\hline 1955 & $\begin{array}{l}\text { Cueva de } \\
\text { Potrerillos, SLP } \\
\text { (1) }\end{array}$ & 1 & 0 & $0(0-84)$ \\
\hline 1964 & $\begin{array}{l}\text { Cueva de } \\
\text { Potrerillos, SLP } \\
(46)\end{array}$ & 46 & 0 & $0(0-8)$ \\
\hline 1965 & $\begin{array}{l}\text { El Sotano, SLP } \\
\text { (4) }\end{array}$ & 4 & 0 & $0(0-52)$ \\
\hline 1968 & $\begin{array}{l}\text { W of El } \\
\text { Madroño, Qro } \\
\text { (40) }\end{array}$ & 40 & 0 & $0(0-13)$ \\
\hline 1969 & $\begin{array}{l}\text { W of El } \\
\text { Madroño, Qro } \\
\text { (38), Cueva de } \\
\text { Potrerillos, } \\
\text { SLP (43) }\end{array}$ & 81 & 1 & $1.2(0-7)$ \\
\hline 1970 & $\begin{array}{l}\text { W of El } \\
\text { Madroño, Qro } \\
\text { (46) }\end{array}$ & 46 & 1 & $2.2(0-12)$ \\
\hline 1971 & $\begin{array}{l}\text { W of El } \\
\text { Madroño, Qro } \\
\text { (10) }\end{array}$ & 10 & 0 & $0(0-26)$ \\
\hline
\end{tabular}


Cueva de la

$1975 \quad$ Iglesia, SLP $33 \quad 3 \quad 9.1(3-24)$

$\mathrm{W}$ of $\mathrm{El}$

1979 Madroño, Qro 3

0

$0(0-60)$

(3)

$\mathrm{W}$ of El

1981

Madroño, Qro

(1), Cueva de la

1

$50(9-91)$

Iglesia, SLP (1)

Cueva de la

Iglesia, SLP

$1982 \quad$ (5), Cueva de 9

1

$11.1(3-44)$

Potrerillos, SLP

(4)

2012

Cueva el Coni,

Hgo (1)

$1 \quad 0$

$0(0-84)$

Total

279

7

$2.5(1-5)$ 


\section{Table 3(on next page)}

Species and locality information, sample sizes, and results of qPCR Bd and Bsal assays for amphibians encountered during fieldwork.

Bold font indicates samples that tested positive for Bd. 


\begin{tabular}{|c|c|c|c|c|c|c|c|c|}
\hline Species & Locality & $\begin{array}{l}N \\
\text { Bd }\end{array}$ & Bd+ & $\begin{array}{l}\% \text { Bd } \\
\text { prevalence } \\
(95 \% \text { CI })\end{array}$ & $\begin{array}{l}\text { Mean } \\
\text { Infection } \\
\text { intensity } \\
\text { (GE) }\end{array}$ & $\begin{array}{l}N \\
\text { Bsal }\end{array}$ & Bsal+ & $\begin{array}{l}\text { \% Bsal } \\
\text { prevalence } \\
(95 \% \text { CI })\end{array}$ \\
\hline
\end{tabular}

\section{Salamanders}

Chiropterotriton

El Con

33 (4-78)

123.5

$4 \quad 0$

$0(0-60)$

magnipes

Hgo

Chiropterotriton

La

92

$22(3-60)$

392

50

$0(0-52)$

magnipes

Trinidad,

SLP

Chiropterotriton

El Coni

3

Hgo

mosaueri

El Coni

Aquiloeurycea sp.

Hgo

\section{Frogs}

Craugastor

$\begin{array}{lllll}\text { Cueva la } & 2 & \mathbf{5 0} & \mathbf{5 0}(\mathbf{1 3}-98) & \mathbf{1 7 7 9 . 5}\end{array}$

decoratus

Barranca,

SLP

Eleutherodactylus

El Con

cystignathoides

Hgo

Eleutherodactylus

Cueva de

cystignathoides

la Iglesia,

$$
\text { SLP }
$$

Total

$$
29827.6(13-
$$

140

$0(0-23)$

47) 


\section{Figure 1}

Map of caves where searches for $C$. magnipes were conducted.

Historical sites where $C$. magnipes was collected are shown as blue circles, sites where $C$. magnipes was recorded during our surveys as blue stars, and caves where $C$. magnipes was not previously reported and was not detected in our survey as red squares. Locality numbers correspond to those in Table 1. Historic and new records of $C$. magnipes encompass entire range of the species, and no populations are known between population 13 in Hidalgo and the rest of the species' range. 


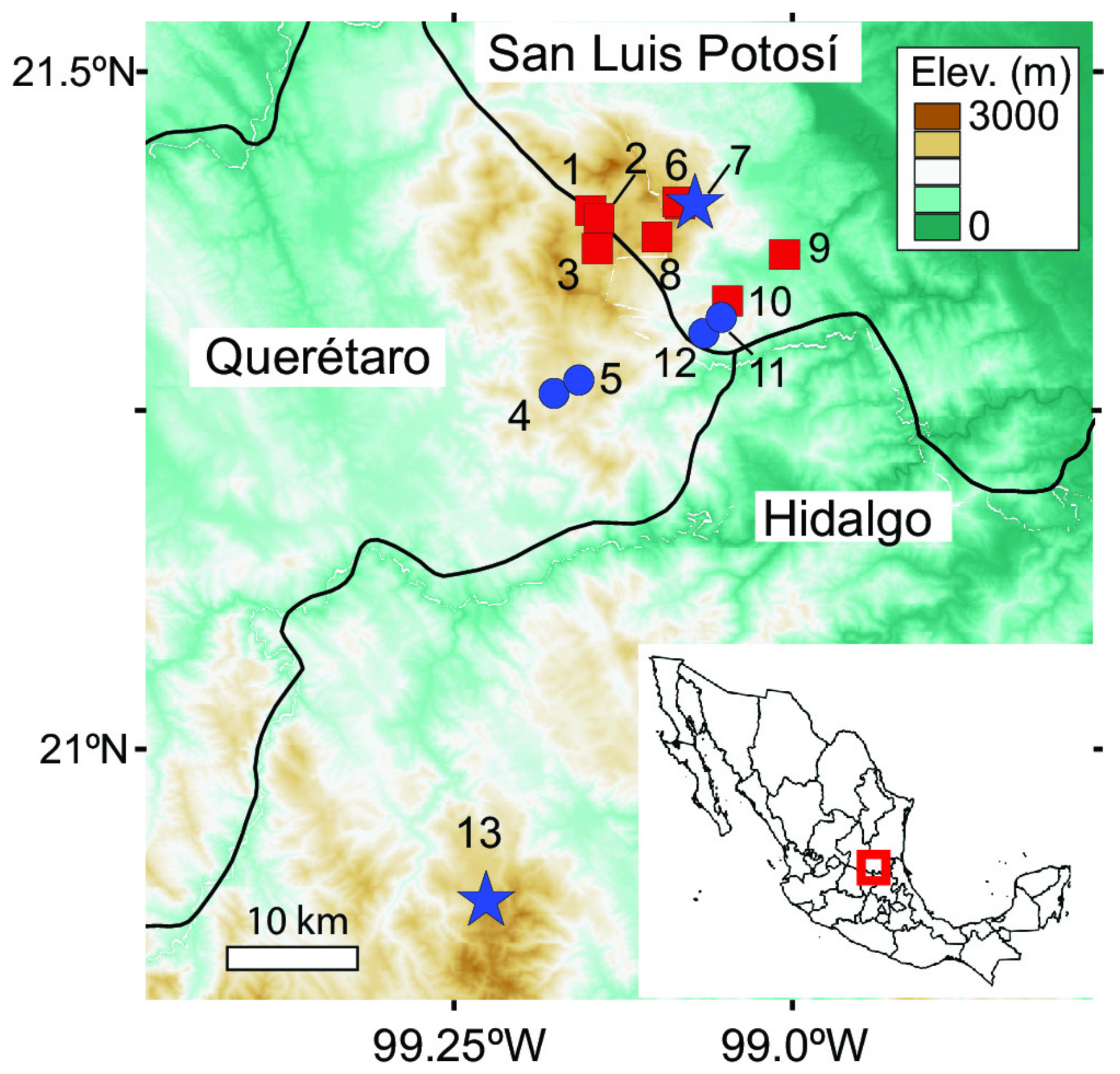

